represented. Twenty-eight papers were presented, and they are reproduced in full in the present volume together with the relevant discussion. The book opens with a number of addresses of welcome made at the actual conference, which gives a background to this new technology and to the conference. Then follow a number of survey papers covering British, American and French work on microminiaturization, together with an account of a few specialized topies, for example, pneumatic amplifiers.

The second section of the book is devoted to a number of papers on the micromodule approach to microminiaturization, based on using sub-miniature components, printed circuits and a high packaging density of components. The third section is devoted to microcircuits, which are substrates on which passive elements are deposited (usually by evaporation) and where active elements, for example, diodes, transistors, etc., are attached either to the surface, or set into holes in the substrate, whereas the fourth section of the book is devoted to solid circuits, in which a single crystal of silicon is fabricated to act as a complete circuit involving resistors, eapacitors, diodes, and transistors.

The book gives a most useful account of the subject, as would be expected as many of the authors are the foremost authorities on the matter, and it is a book that can be recommonded to everyone interested in microminiaturization. Apart from providing full details of the technical developments, there is a great deal of information on the pros and cons of mierominiaturization, the different philosophies adopted. as well as details of what might be expected in the future. The book is well printed and illustrated and can be definitely recommended in spite of the high price.

D. TAYLOR

\section{MEMORIES FOR COMPUTING SYSTEMS}

\section{Square-Loop Ferrite Circuitry}

Storage and Logic Techniques. By C. J. Quartly. Pp. vii + 166. (London: Tliffe Books, Ltd.; Englewood Cliffs, N.J.: Prentice-Hall, Ine., 1962.) 42s. net.

\section{Large-Capacity Memory Techniques for Computing Systems}

(ACM Monograph Series.) Pp. viii +440. (New York and London: The Macmillan Company, New York, a Division of the Cromwell-Collier Publishing Company, 1962.) 73s.; 11 dollars.

$\mathrm{H}$ IGH-SPEED digital computers have become considerably faster and larger in the past few years. Most users of digital computers agree that to increase the potential application of computing equipments it is necessary to increase the capacity of the random access memory of the computing system. It should be noted that the development of efficient, high-speed access, highdensity memories can often enhance the problem-solving ability of a computer with little additional modification and so is very attractive economically. It is for these reasons that there is considerable activity in many places in exploring novel methods of storing information, improving the speed of operation and capacity of conventional stores. It is, therefore, extremely satisfactory to see these two additions to the literature on the subject.

The book by C. J. Quartly deals with the use of ferrite materials with rectangular hysteresis loops as memory stores for computers. Initially, as is well known, the development of high-speed digital computers was seriously handicapped by the lack of a suitable method of storing information, but this situation was changed with the discovery of a ferrite with the required rectangular hysteresis loop, and short access time stores are now available which are highly reliable, relatively inexpensive and are capable of meeting the requirements of speed of operation.
The developments in this field have been relatively fast, and as Quartly has been concerned personally with many of the developments (he is an engineer at one of the firms manufacturing and marketing ferrite cores), he is able to speak from personal knowledge about most of what he writes. The result is a very readable book outlining the historical developments, the properties of square-loop matorials, the development of the various systems, for example, coincident drive storage, word addressed systems, etc. There are special chapters on non-destructive read-out, the construction of stores, and circuits uscd in storage systems. Naturally in discussing drive circuits, etc., the author only considers transistor circuits.

The second volume comprises the proceedings of the symposium on "Large-Capacity Memory Techniques for Computing Systems", which was sponsored by the U.S. Office of Naval Research and held in May 1961.

Unfortunately, only the papers presented at the symposium have been included in this printed account of the proceedings. It would have been still more useful if the editor could have included an account of the critical discussion which the presentation of the papers caused.

Altogether 30 papers were presented and are printed in full in the present volume. These detail special types of ferrite core memories for large capacity, the consideration of the many theoretical points which the development of large-capacity digital memories with very short access time introduces, and consideration of many novel types of store, for example, electron spin stores, as well as progress reports on many of the now types of store which are becoming available, for example, thin magnetic films. cryogenic memories, ferro electric types of storage, 'twister' memories, etc.

This is an interesting collection of papers which all concerned with the further development of high-speed digital computers will find of value, and allows the relative evaluation of these various techniques to be made in regard to their probable utilization in the computing field in the future.

D. TAYLOR

\section{TWO VIEWS OF FLUORINE CHEMISTRY}

The Manufacture and Use of Fluorine and Its Compounds By Dr. A. J. Rudge. Pp. xiii $+87+11$ plates. (London: Oxford University Press, 1962. Published under the auspices of Imperial Chemical Industries, Ltd.) $10 s$. 6d. net.

Chemistry of Organic Fluorine Compounds

By Milos Hudlický. Pp. 536. (London and New York: Pergamon Press, 1961.) 60s. net.

$\mathrm{O}^{\mathrm{N}}$ $\mathrm{NE}$ becomes rather tired of being swamped by the mass of badly written, often rather useless chemistry books and new pseudo-specialist journals spawned by publishers week after week, so it is a pleasure to find two books which come into the distinctly useful eategory. Both deal with fluorine chemistry, but from quite different points of view and with different objectives. Dr. Rudge writes as a physical and inorganic chemist to demonstrate to young students that the same principles cover chemistry learnt at school and chemistry as applied in industry. Dr. Hudlický brings his enthusiasm for synthetic organic chemistry, and writes for the research worker.

Dr. Rudge's book is the fourth published under the auspicos of Imperial Chemical Industries, Ltd., and fully maintains the excellent standard of the first three. It provides for the first time an authoritative yet readable account of the manufacture of fluorine and hydrogen fluoride, together with a brief survoy of the preparation and uses of a number of other inorganic and organic fluorine compounds. Sixth-form pupils and first- and second-year university or technical college students need no longer read and memorize the out-of-date, inaccurate 